\title{
A RECOMENDAÇÃO DA UNIÃO EUROPÉIA, DE 11 DE JUNHO DE 2013, SOBRE AS AÇÕES COLETIVAS"
}

\author{
Aluisio Gonçalves de Castro Mendes** \\ Larissa Clare Pochmann da Silva****
}

\begin{abstract}
RESUMO
As ações coletivas ocupam a agenda europeia através de diretivas, mas, em 11 de junho de 2013, fruto de trabalhos iniciados no ano de 2011, teve advento um Comunicado e uma Recomendação da Comissão Europeia sobre o tema. O objetivo foi aprimorar o acesso à Justiça mediante a adoção de regras comuns para as ações coletivas no bloco, devendo, obrigatoriamente, mediante o estabelecimento de prazos, os países que não possuem previsão de processo coletivo implementá-la nos termos previstos e os que possuem adequar suas disposições ao texto da Recomendação. Estas disposições são relevantes para o sistema
\end{abstract}

Fecha Recibido: abril 11 de 2014 • Fecha Aceptado: mayo 28 de 2014

* Artigo inédito.

** Pós-Doutor pela Universidade de Regensburg, Alemanha. Doutor em Direito pela UFPR. Mestre em Direito pela UFPR. Mestre em Direito pela Johann Wolfgang Goethe Universität (Frankfurt am Main, Alemanha). Especialista em Direito Processual Civil pela Universidade de Brasília (UnB). Professor nos cursos de graduação e pós-graduação da Universidade do Estado do Rio de Janeiro (UERJ) e da Universidade Estácio de Sá (Unesa). Diretor do Instituto Brasileiro de Direito Processual (IBDP). Membro do Instituto Ibero-americano de Direito Processual, da Associação Brasil-Alemanha de Juristas e da International Association of Procedural Law. Ex-Promotor de Justiça. Desembargador Federal. Diretor de Cursos e Pesquisas da Escola da Magistratura Regional Federal da 2a Região (EMARF). Membro do Conselho Superior da Escola Nacional de Formação e Aperfeiçoamento de Magistrados (Enfam).

*** Graduada em Direito pela Universidade do Estado do Rio de Janeiro (UERJ). Mestre e Doutoranda em Direito pela Universidade Estácio de Sá (UNESA). Professora no curso de graduação da Universidade Candido Mendes (UCAM), campi Tijuca, Méier e Jacarepaguá. Advogada. 
processual coletivo e já começaram a ser implementadas, proporcionando um maior destaque ao seu papel na sociedade contemporânea.

Palavras chave: Ação Coletiva; União Europeia; Uniformização; Recomendação.

\begin{abstract}
The collective action suits have kept busy the European agenda for some time through directives, but only on June 11, 2013, outcomes from a work started two years before, the European Commission introduced a Statement and a Recommendation on the theme. The objective was to improve access to justice through the adoption of common rules for collective actions in the block, imposing that, within the deadlines, countries without provisions for the collective actions implement it accordingly, and those, which happen to already have them, adapt their provisions to the commands in the recommendation. Those provisions are relevant to the collective procedural system, and they have already started to be implemented, applying greater emphasis on its role in contemporary society.
\end{abstract}

Key words: Collective Action; European Union; Standardizing; Recomendation.

\title{
INTRODUÇÃO
}

As ações coletivas não são um tema recente no cenário internacional e há algum tempo ocupam a agenda europeia, especialmente em matéria consumerista. A edição de diversas diretivas e de Livros de proteção dos consumidores marcaram as referências ao processo coletivo no bloco. A previsão das diretivas, porém, precisava ser transposta ao ordenamento de cada um dos seus 27 Estados Membros, o que gerava maior ou menor grau de flexibilização nas suas disposições. Eram disposições do bloco que acabavam, em apertada síntese, observadas com variações em cada membro.

Em 11 de junho de 2013, viabilizou-se o projeto de um modelo de ação coletiva para a União Europeia. No mesmo dia, a Comissão Europeia editou uma comunicação e uma Recomendação, fruto de pesquisas e consultas que se iniciaram em 2011. A Recomendação estabeleceu o prazo de 25 de julho de 2015 para ser implementada e com a previsão da obrigatoriedade de fornecimento de resultado anualmente a partir de 26 de julho de 2016, para a reapreciação de sua aplicação até 26 de julho de 2017, estabelece disposições que devem ser observadas, construindo um modelo de ações coletivas para a União Europeia, e pode contribuir para a efetividade do processo coletivo. 
Devido à relevância do tema, o presente artigo se concentrará na análise da Recomendação, destacando a sua relevância para o processo coletivo europeu; a previsão da tutela inibitória e da tutela ressarcitória; a legitimidade para as ações coletivas; a admissibilidade de uma ação coletiva e o Cadastro de Ações Coletivas, as custas processuais, honorários advocatícios e o financiamento ao litígio. Por fim, será analisada a repercussão da Recomendação no cenário europeu, como, pouco tempo após seu advento, os países já começaram a adequar suas disposições processuais coletivas de forma a observar as determinações previstas no texto.

\section{A RELEVÂNCIA DA RECOMENDAÇÃO DE 11 DE JUNHO DE 2013 PARA O CENÁRIO dO PROCESSO COLETIVO EUROPEU}

Em 11 de junho de 2013, teve advento, no âmbito da União Europeia, a Recomendação $^{1}$ da Comissão sobre os princípios comuns que devem reger os mecanismos de tutela coletiva inibitórios e indenizatórios no âmbito dos Estados Membros em relação às violações de direitos garantidos pelo bloco. A referida recomendação foi editada no mesmo dia da comunicação ao Parlamento Europeu, ao Conselho, ao Comitê Econômico e Social Europeu e ao Comitê das Regiões ${ }^{2}$.

A comunicação fez um inventário das medidas tomadas até a data, objetivando assegurar um conjunto de soluções que facilitem uma reparação eficaz, através de um direito processual simplificado e que assegure uma boa relação custo-eficácia para o litígio não apenas no âmbito de cada país, como também em relação a danos transfronteiriços. A Comissão destacou que o bloco deveria ser capaz de poder resolver efetivamente um grande número de pedidos individuais de indenização, promovendo, assim, a economia processual; ser capaz de oferecer uma resposta aos litigantes em um prazo razoável e prever garantias contra a litigância abusiva.

Consagrou a necessidade de garantia de uma tutela ressarcitória em todos os países membros, medida esta repudiada, em sua origem, pelo bloco, por uma

UNIÃO EUROPEIA. Recomendação sobre Ação Coletiva (2013). Disposição sobre ações coletivas. Bruxelas:Justiça. Disponível em http://ec.europa.eu/justice/newsroom/civil/ news/130611_en.htm. Acesso em: 13 abr. 2014.

2 UNIÃO EUROPEIA. Rumo a um quadro jurídico horizontal europeu para a tutela coletiva. Disponível em https://toad.eesc.europa.eu/ViewDoc.aspx?doc...2013_00_00. Acesso em 12 abr. 2014. 
crítica ao modelo das class actions for damages norte-americanas ${ }^{3}$, a verificação da representatividade adequada, que se admite deixar tal critério tanto à aferição das leis como dos tribunais, bem como se sugeriu a adoção do modelo de opt in, com ampla publicidade sobre a ação coletiva, e a adoção de mecanismos alternativos de solução de conflitos para os litígios coletivos.

A recomendação, por sua vez, destaca, a partir da relevância de assegurar o acesso à Justiça, a utilização do processo coletivo como mecanismo adequado para prevenir e punir violações ao direito do consumidor, da concorrência, da proteção do meio ambiente, de dados, de serviços financeiros e dos investidores, com o estabelecimento de um modelo comum para as ações coletivas no âmbito europeu. Destaca, ainda, a necessidade dos Estados-Membros adotarem medidas para a implementação da recomendação, que devem ocorrer até 26 de julho de 2015, com as estatísticas judiciais e extrajudiciais apresentadas no ano seguinte, para reavaliação da recomendação até 26 de julho de 2016.

As medidas foram fruto de um intenso debate ${ }^{4}$, após a Consulta Pública realizada pela Comissão Europeia em $2011^{5}$, a Resolução do Parlamento Europeu, de 2 de fevereiro de $2012^{6}$ e a própria análise da Comissão. Tanto a consulta pública intitulada "Rumo a uma abordagem europeia coerente sobre a ação coletiva” como a Resolução do Parlamento Europeu apontaram a necessidade de um sistema de ação coletiva a nível da União Europeia ${ }^{7}$, com princípios comuns com o sistema jurídico do bloco e as ordens jurídicas dos seus 27 Estados-Membros, proporcionando um acesso uniforme à Justiça mediante o recurso ao referido sistema, com previsão específica, mas não exclusiva, às violações dos direitos dos consumidores.

3 RUSSELL, Tiana Leia. "Exporting Class Actions to the European Union". Boston University International Law Journal. Boston: Boston University, vol. 28, n. 1, primavera de 2010, p. 152-158.

4 STADLER, Astrid. “The Commission's Recommendation on common principles of collective redress and private international law issues". Disponível em http://www.nipr-online.eu/ Artikel.aspx?id=3112. Acesso em 14 abr. 2014.

5 UNIÃO EUROPEIA. Consulta Pública: Rumo a uma abordagem europeia coerente sobre a acção colectiva. Bruxelas: Documento de Trabalho dos Serviços da Comissão, 2011. Disponível em http://ec.europa.eu/dgs/health_consumer/dgs_consultations/ca/docs/cr_consultation_ paper_pt.pdf. Acesso em: 13 abr. 2014.

6 PARLAmento EUROPEU. Resolução do Parlamento Europeu, de 2 de fevereiro de 2012, sobre "Rumo a uma abordagem europeia coerente sobre a ação coletiva. Disponível em http://www.europarl.europa.eu/sides/getDoc.do?pubRef=-//EP//TEXT+TA+P7-TA-20120021+0+DOC+XML+V0//PT. Acesso em 20 abr. 2014.

7 HODGES, Christopher; MONEY-KYRLE, Rebecca. European Collective Action: Toward Coherence? Maastricht Law Journal of European and Comparative Law. Maastricht: Maastricht Law School, vol. 19, n. 4, 2012, p. 478. 
A Comissão preocupou-se, então, em incentivar a ação inibitória como mecanismo para resguardar os direitos assegurados no bloco, especialmente em matéria ambiental, e uniformizar a ação coletiva reparatória, não exclusivamente, mas com ênfase em matéria consumerista ${ }^{8}$. Não o fez por meio de diretivas, que precisam ser transpostas para o direito nacional, com flexibilidade para a adequação dessas previsões à realidade de cada país", como já ocorria desde 1993 no histórico das ações coletivas $^{10}$ na União

$8 \quad$ HARBOUR, Laurel J.; SHELLEY, Marc E. “The Emerging Euroepan Class Action: Expanding Multi-Party Litigation to a Shrinking World”. 2006 ABA Annual Meeting, Section of Litigation, August 3-6, 2006, The Emerging European Class Action. Disponível em http:// www.americanbar.org/tools/digitalassetabstract.html/content/dam/aba/migrated/litigation/mo/premium-lt/prog_materials/2006_abaannual/04b.pdf. Acesso em: 13 abr. 2014 e MULHERON, Rachel. The case for an opt-out class action for European Member States: a legal and empirical analysis. Current Law Journal Content. Washington: Washington Lee Law School, vol. 15, n. 3, verão de 2009, p. 410-411.

9 Segundo o direito europeu, as diretivas fixam metas a serem atingidas pelos Estados-Membros, com o objetivo de uniformizar os direitos nacionais. Podem se dirigir a alguns membros ou a todos eles. Não possuem efetividade imediata, prevendo um prazo como limite para serem transpostas para os direitos nacionais. Porém, há uma grande "margem de manobra" para os Estados Membros, ao realizarem a transposição, considerarem as realidades nacionais. (A referida informação pode ser obtida em COMISSÃO EUROPEIA. Directivas - Definições. Bruxelas: Aplicação do direito da União Europeia. Disponível em http://ec.europa.eu/eu_law/ directives/directives_pt.htm. Acesso em: 13 abr. 2014)

10 Merece destaque as medidas adotadas a partir de 1993 em relação ao processo coletivo no bloco. Nesse ano, a Diretiva $n^{\circ} 13$, trouxe a previsão de harmonização de legislações nacionais com a tutela consumerista no caso de cláusulas abusivas em contrato de massa. A referida diretiva trata do direito coletivo dos consumidores que realizam contratos com cláusulas de adesão abusivas, exemplificando com um elenco mínimo de cláusulas consideradas como abusivas. Em 1998, a Diretiva 27 trata da ação inibitória para a tutela dos interesses coletivos dos consumidores, prevendo a proteção consumerista em âmbito jurisdicional e administrativo, com publicidade das decisões e previsão de multa como medida coercitiva para cumprimento das decisões. Em 2001, o Livro Verde se preocupou com a questão da defesa do consumidor e as soluções a adotar para uma harmonização da regulamentação comunitária. No período de 2002 a 2006 houve uma Ação para a Defesa do Consumidor, sendo que em a Diretiva 29 tentou fortalecer os direitos dos consumidores, oferecendo a mesma proteção aos consumidores em todos os países-membros da União Europeia e, ainda nesse ano, foi editado o Livro Verde para a Defesa da Concorrência. Em 2007 e em 2008 intensificaramse os debates sobre as ações coletivas na União Europeia, com a preocupação da eficiência do sistema de resolução de conflitos. Em março de 2007, a Comissão Europeia lançou dois estudos sobre a tutela coletiva. O primeiro destes estudos avalia a eficácia e a eficiência da reparação de sistemas coletivos nacionais. Em 2008, a Comissão Europeia publicou um Livro Branco, intitulado "Do Consumidor de Compensação e de Negócios Vítimas de Infrações às Regras da Concorrência". Esse livro recomenda uma expansão de "ações de classe" em toda a União Europeia, dessa vez adotando um modelo de opt in ao formular propostas para 
Europeia $^{11}$, mas, para sua observância, dispôs por meio de Recomendação, com previsão expressa de sua obrigatoriedade, através do prazo de 2 (dois) anos para sua implementação, 3 (três) anos para apresentação de estatísticas sobre seu funcionamento e até 4 (quatro) anos para eventual revisão ${ }^{12}$.

Trata-se de nítida preocupação em uniformizar as disposições para assegurar que o direito processual coletivo seja capaz de tutelar de forma eficaz e com baixos custos os direitos previstos no âmbito do bloco ou os casos transfronteiriços, relacionando o processo às perspectivas de avanço na integração.

As ações coletivas são um relevante instrumento para a efetivação do direito material, proporcionando que a totalidade, ou pelo menos uma quantidade significativa, alcance seus direitos, fazendo com que não haja, por parte do cometedor do ato ilícito, uma apropriação indevida, dimensionada pelas dificuldades de acesso à Justiça ${ }^{13}$. Um mesmo modelo de ações coletivas nos 27 países Membros garantirá, portanto, que o processo seja capaz de assegurar os direitos previstos pelo bloco.

Além disso, disposições sobre o processo coletivo coadunam-se com a disposição do art. 292 do Tratado sobre o Funcionamento da União Europeia, especificamente de facilitação do acesso à Justiça, e garantia de um nível elevado de proteção do consumidor. O desequilíbrio entre as partes pode ser, também, um fator decisivo para que a parte lesada deixe de buscar individualmente a

aumentar a eficiência da reivindicação dos consumidores vítimas de danos. No mesmo ano, foi publicado, ainda, o Livro Verde sobre a tutela coletiva dos consumidores, em que destacou a importância de medidas de reparação dos consumidores, inclusive no âmbito coletivo. $\mathrm{O}$ Livro Verde não aborda a tutela coletiva das vítimas de infrações à legislação comunitária no domínio antitruste, devido à natureza específica do direito da concorrência e da noção mais ampla do conceito de vítimas, que estão no Livro Branco. Entre 8 de maio e 3 de julho do ano de 2009, foi apresentada uma consulta pública para apresentar a primeira análise do impacto das opções à luz do Livro Verde sobre a tutela coletiva dos consumidores e para reunir mais informações, de preferência com casos concretos e estatísticas. Em fevereiro de 2011, seguiram-se os passos para a elaboração da Recomendação objeto de análise deste trabalho.( HODGES, Christopher. Summary of European Union Developments. [S.l.: s.n. Disponível em http://globalclassactions.stanford.edu/content/global-class-actions-project-summary-european-developments. Acesso em: 13 jul. 2013).

11 GRINOVER, Ada Pellegrini; WATANABE, Kazuo; MULLENIX, Linda. Os Processos Coletivos nos Países de Civil Law e Common Law: uma análise do direito comparado. São Paulo: RT, 2007. p. 20-24.

12 STADLER, Astrid. The Commission's Recommendation on common principles of collective redress and private international law issues. Disponível em http://www.nipr-online.eu/ Artikel.aspx?id=3112. Acesso em 14 abr. 2014.

13 MENDES, Aluisio Gonçalves de Castro. Ações coletivas e meios de resolução coletiva de conflitos no direito comparado e nacional. 3. ed. São Paulo: RT, 2012, pp. 41-42. 
proteção judicial ou, então, a própria correlação de forças na relação processual. A tendência é que o causador da lesão disponha de mais recursos materiais e humanos e, portanto, em tese, esteja mais bem preparado para o embate, provido que estará para a contratação de profissionais de qualidade e para a produção de provas que lhe sejam favoráveis. Nesse sentido, incentivar a solução pela via das ações coletivas, conforme previsto no texto da recomendação, se bem estruturadas, pode superar esses entraves.

A preocupação não apenas em definir um modelo de ações coletivas, mas, principalmente, de efetivar o modelo implementado, restou nítida nas disposições sobre custos processuais, evitando que dificultem o ajuizamento ou prosseguimento de ações coletivas, bem como na combinação de formas judiciais e extrajudiciais para a solução de conflitos coletivos. Paralelamente, para evitar abusos nas ações coletivas, foram previstos filtros para evitar abusos nas ações coletivas, as denominadas salvaguardas ${ }^{14}$. Estas disposições da Recomendação passarão a ser abordadas.

\section{A TUtela inibitória e a tutela Ressarcitória}

A tutela inibitória e uma ação de conhecimento, de natureza preventiva, destinada a impedir a prática, a repetição ou a continuação do ilícito, de uma violação a direito. Não há a exigência da probabilidade do dano, contentando-se com a simples probabilidade de ilícito. A ação inibitória pode atuar de três maneiras distintas. Em primeiro lugar, para impedir a prática de ilícito, ainda que nenhum ilícito anterior tenha sido produzido pelo réu. Em segundo lugar, pode impedir a consecução da lesão e, em terceiro lugar, obstar a continuação da lesão ${ }^{15}$. Já a tutela ressarcitória busca reparar o dano, quantifica a lesão para que seja realizada sua reparação pelo equivalente pecuniário correspondente.

A Recomendação assegura tanto uma tutela inibitória como uma tutela ressarcitória, que devem ser previstas por todos os países membros. Há a referência a princípios comuns e diferenças entre as duas medidas na estrutura de seu texto. São aspectos comuns entre as duas tutelas a legitimidade para o ajuizamento da ação coletiva (arts. $4^{\circ}$ a $7^{\circ}$ ); a admissibilidade de uma ação como coletiva (arts. $8^{\circ}$ e $9^{\circ}$ ); informações sobre a ação ajuizada (arts. 10 a 12); o reembolso das custas judiciais pela parte vencida à parte vencedora (art. 13),

14 HODGES, Christopher. Collective Redress: A Breakthrough or a Damp Sqibb? Trabalho no prelo, p. 2.

15 MARINONI, Luiz Guilherme. Tutela Inibitória e Tutela de Remoção do Ilícito. Disponível em http://www.abdpc.org.br/abdpc/artigos/Luiz\%20G\%20Marinoni(2)\%20-\%20formatado. pdf. Acesso em 8 abr. 2014. 
financiamento do litígio (arts. 14 a 16), as disposições sobre casos transfronteiriços (arts. 17 e 18), bem como o item VI, "Informações Gerais", que dispõe sobre um registro nacional de ações coletivas no âmbito de cada país membro e o item VII, “Supervisão e Informação”, relativos à implementação da Recomendação.

A tutela inibitória não é um instrumento novo para a União Europeia. A consulta pública realizada em $2011^{16}$ já indicou que, quando do advento da Recomendação, todos os países já contavam com algum tipo de proteção capaz de viabilizar a ação coletiva inibitória em seu ordenamento. Tal previsão foi até mesmo uma decorrência da exigência já existente no bloco que os EstadosMembros prevejam a ação inibitória coletiva em determinados domínios, como no caso do direito do consumidor, mediante previsão do Regulamento (CE) n. ${ }^{\circ}$ 2006/2004, relativo à cooperação no domínio da defesa do consumidor , e da Diretiva 2009/22/CE. Porém, a previsão da Recomendação não foi meramente reiterar a manutenção da tutela inibitória no cenário europeu. Como registrado no art. 12 da Resolução do Parlamento Europeu ${ }^{17}$, era necessário aprimorar a tutela inibitória nas ações coletivas, especialmente em matéria ambiental.

Nesse sentido, a tutela inibitória possui sua referência específica na Recomendação. O item 11 das considerações do texto da Recomendação apenas traz sua abordagem por mera oposição ao conceito de tutela ressarcitória, ao dispor que não permite indenização em relação à prática ilícita. Já nas definições, o item 3, letra a, apresenta-se como a possibilidade de cessar um comportamento ilegal, em sentido amplo, mas sem, a priori, especificar as suas três situações de cabimento.

Seus princípios específicos estão previstos no item IV, "Princípios Específicos da Forma Inibitória de Tutela Coletiva”, nos artigos 19 e 20. No artigo 19, a Recomendação admite, se necessário, a adoção de um procedimento sumário pelos tribunais, de forma a contribuir com uma resposta célere, admitindo tal procedimento tanto para evitar, como para fazer cessar a prática do ilícito. Já o art. 20 trata da preocupação com a efetividade da tutela inibitória, trazendo a possibilidade de multa para respeito à decisão ou outra medida considerada adequada.

16 UNIÃO EUROPEIA. Consulta Pública: Rumo a uma abordagem europeia coerente sobre a acção colectiva. Bruxelas: Documento de Trabalho dos Serviços da Comissão, 2011. Disponível em http://ec.europa.eu/dgs/health_consumer/dgs_consultations/ca/docs/ cr_consultation_paper_pt.pdf. Acesso em: 13 abr. 2014.

17 PARlamento EUROPEU. Resolução do Parlamento Europeu, de 2 de fevereiro de 2012, sobre «Rumo a uma abordagem europeia coerente sobre a ação coletiva. Disponível em http://www.europarl.europa.eu/sides/getDoc.do?pubRef=-//EP//TEXT+TA+P7-TA-20120021+0+DOC+XML+V0//PT. Acesso em 20 abr. 2014. 
Já a tutela ressarcitória foi prevista com atenção ao avanço no processo de integração do bloco, a partir da preocupação de que danos de bagatela e da possível insuficiência das legislações nacionais. A preocupação era manter a boa prática das empresas no cenário da concorrência europeu e assegurar o respeito aos direitos do consumidor, mas que, em caso de qualquer dano, as vítimas pudessem ser prontamente reparadas, sem esbarrar na casuística da reparação de danos de cada ordenamento de Estado membro. Isso porque a maioria dos Estados-Membros introduziu procedimentos de ação coletiva ressarcitória, mas os modelos variam consideravelmente em determinados domínios, seja na limitação ou não de matérias que permitem a busca de reparação pela via coletiva; seja em relação à legitimidade, aos sistemas de vinculação aos efeitos da coisa julgada e até mesmo à utilização de mecanismos alternativos de solução de litígios (art. 17 da Resolução do Parlamento Europeu ${ }^{18}$ ).

No texto, sua primeira referência está no item 1, "Finalidade e Objeto", permitindo que as partes lesadas obtenham uma reparação em situações de dano em massa resultante de violações de direitos. É possível o requerimento de indenização em qualquer tribunal nacional (art. $3^{\circ}, 3$ da Recomendação).

Sua regulamentação, no Título V, "Princípios Específicos da Forma Indenizatória da Tutela Coletiva", é mais extensa e compreende a referência aos sistemas de vinculação aos efeitos da coisa julgada na ação coletiva (arts. 21 a 24); a adoção de mecanismos alternativos de solução de litígios e a celebração de acordos coletivos (arts. 25 a 28); o patrocínio judiciário e os honorários advocatícios (arts. 29 e 30); a proibição de indenizações punitivas (art. 31); o financiamento ao litígio (art. 32) e as ações de seguimento coletivas (arts. 33 e 34), estas últimas posteriormente alicáveis, por força de recomendação posterior, também à tutela inibitória. Merece destaque o art. 31, que veda indenizações punitivas, afirmando que a indenização deve se limitar ao dano causado, como mais uma medida para evitar abusos no direito de litigar. Trata-se de uma salvaguarda processual ${ }^{19}$, para evitar abusos nas ações coletivas, impedindo o uso da ação coletiva como forma de enriquecimento para obter vultosas quantias em espécie.

18 PARLAMENTO EUROPEU. Resolução do Parlamento Europeu, de 2 de fevereiro de 2012, sobre «Rumo a uma abordagem europeia coerente sobre a ação coletiva. Disponível em http://www.europarl.europa.eu/sides/getDoc.do?pubRef=-//EP//TEXT+TA+P7-TA-20120021+0+DOC+XML+V0//PT. Acesso em 20 abr. 2014.

19 HODGES, Christopher, MONEY-KIRLE, Rebecca. Safeguards in Collective Actions. Oxford: The Foundation for Law, Justice and Society (FLJS), p. 2. Disponível em www.fljs.org. Acesso em 25 mar. 2014. 


\section{A Legitimidade PARA AS AÇÕES COLETIVAS}

Com o advento da recomendação, no terceiro título, "Princípios Comuns à Forma Inibitória e Indenizatória da Tutela Coletiva", no subitem "Legitimidade para intentar uma ação representativa", o texto não tratou sobre a necessidade de identificação dos membros dos grupos, sempre que possível, mas trouxe duas disposições sobre os legitimados: uma no âmbito de ações coletivas no bloco e outra especificamente para os casos de ações coletivas transfronteiriças.

No primeiro caso, regulou apenas sobre requisitos que devem ser preenchidos pelas entidades representativas, requisitos estes cumulativos que devem ser observados pelos Estados-Membros, sem prejuízo de outras exigências nos direitos nacionais. O primeiro requisito é a entidade não possuir fins lucrativos; o segundo é a existência de uma relação direta entre os objetivos principais da entidade e os direitos cuja tutela se pretende, o que se denomina pertinência temática, e o terceiro requisito é a entidade ser dotada de capacidade, tanto econômica, como de suporte humano e de conhecimentos jurídicos para o litígio. Já se a entidade não for cadastrada, caberá às autoridades governamentais, ou ao próprio tribunal, realizarem uma certificação $a d$ hoc para o ajuizamento de uma ação.

No segundo caso, ao tratar dos casos transfronteiriços, no art. 17, admite-se a legitimidade de entidades representativas estrangeiras ou de grupos estrangeiros, desde que sejam designados por algum Estado membro como legitimados para as ações coletivas (art. 18).

A preocupação em relação ao sistema de vinculação e o recebimento de informações sobre a ação coletiva não foi abordada pela Recomendação dentro do subitem legitimidade, mas sim no momento relacionado à admissibilidade $\mathrm{e}$ ao prosseguimento de uma ação coletiva.

\section{A AdMissibilidade dA Ação Coletiva, AS INFOrmaÇões E O CADASTRO DE AÇões COLETIVAS}

Uma das preocupações quando da elaboração da Recomendação era de garantir a informação sobre a ação coletiva ajuizada, de forma que as vítimas pudessem aderir ao processo coletivo.

A Recomendação não aborda propriamente a necessidade de um processo de certificação de uma ação como coletiva, até mesmo porque não há uniformidade sobre o tema: alguns países preveem um processo de certificação com possibilidade de recurso, outros apenas o processo de certificação de uma ação como 
coletiva e outros não aludem à certificação ${ }^{20}$. Aborda, nos artigos $8^{\circ}$ e $9^{\circ}$, apenas que se verifique a presença de condições para a ação coletiva, sem especificar que condições são essas, de forma que se torna incabível pensar na existência de alguma condição específica. Essa verificação é atribuída como função de cada tribunal, para indeferir, de plano, ações manifestamente infundadas.

Porém, determinadas ações coletivas só podem ter seu início, nos termos do art. $3^{\circ}$ da Recomendação, "após a adoção, por uma autoridade pública, de uma decisão final que determine ter-se verificado uma violação do direito da União". São as denominadas ações de seguimento, que, em virtude de matéria determinada, autoridades públicas devem verificar se houve uma violação a direito reconhecido no âmbito do bloco. Em caso de ajuizamento de uma ação antes da conclusão, o tribunal poderá suspender o processo até a conclusão administrativa (art. 33). A eventual demora para conclusão da autoridade pública não pode ocasionar a prescrição ou a decadência do direito das vítimas de pleitearem compensação (art. 34).

Essas matérias foram regulamentadas posteriormente, em 26 de julho de 2013, pela Recomendação da Comissão Europeia sobre os Princípios Comuns para Medidas Cautelares e Compensatórias nos Estados Membros em matéria de violações de direito no âmbito do Direito da União Europeia ${ }^{21}$, publicada no Diário oficial da União. É aplicável quando a ação coletiva versar sobre a defesa do consumidor, a concorrência, a proteção do meio ambiente, a proteção dos dados pessoais , a legislação de serviços financeiros e a proteção dos investidores e aplica-se tanto a pretensões inibitórias como ressarcitórias.

Uma vez admitida a ação coletiva, caberá aos Estados (art. 10) assegurar que as entidades representativas garantirão a publicidade das ações coletivas e que a divulgação será feita observando o tipo de lesão causada (art. 11), sem prejudicar as normas de proteção de informações da União Europeia (art. 12), relacionadas a não ser possível a divulgação de informações privilegiadas e nem que possam gerar a manipulação do mercado.

Prevista nos artigos 21 a 24 do item V, "Princípios Específicos da Forma Indenizatória da Tutela Coletiva”, no subitem “Constituição da parte requerente

20 Em relação aos diferentes modelos adotados para as ações coletivas: MENDES, Aluisio Gonçalves de Castro. Ações coletivas e meios de resolução coletiva de conflitos no direito comparado e nacional. 3.ed. São Paulo: RT, 2012, p. 47-187 e SILVA, Larissa Clare Pochmann da. A Legitimidade do Indivíduo nas Ações Coletivas. Rio de Janeiro: GZ, 2013, p. 5-81.

21 COMISSÃO EUROPEIA. Recomendação sobre os Princípios Comuns para Medidas Cautelar e Compensatórias nos Estados Membros em matéria de violações de direito no âmbito do Direito da União Europeia. Disponível em http://ec.europa.eu/justice/civil/ files/c_2013_3539_en.pdf. Acesso em 17 abr. 2014. 
pelo princípio da adesão”, o texto da Recomendação possibilita aos interessados ingressar na ação coletiva, de forma que estejam vinculados aos efeitos da coisa julgada. Trata-se de previsão trazida pelo governo considerada um limitador da utilização abusiva das ações coletivas. O ingresso na ação coletiva dos eventuais lesados é livre a qualquer momento, até a sentença ou outra resolução válida do caso (art. 23), bem como sua exclusão (art. 22), sem prejuízo do prosseguimento da ação individual, mas o réu deve ser comunicado da alteração da classe (art. 24), sem especificação de quem seria esse ônus, do autor ou se seria comunicado pelo próprio tribunal.

Ainda no intuito de assegurar publicidade às ações coletivas, no item VI, "Informações Gerais", subitem "Registro das Ações de Tutela Coletiva”, a Recomendação traz disposições sobre um Cadastro de Ações Coletivas que deve ser implementado no âmbito de cada Estado Membro (art. 35), sem se referir a um único registro no âmbito de todos os 27 países membros para as ações coletivas.

O cadastro deve conter as informações completas e estar acessível pela internet, sendo que, além de informar sobre as ações coletivas, deve explicar aos interessados como obter uma indenização, pela via judicial ou extrajudicial, em nítido incentivo à tutela ressarcitória no âmbito europeu. Evitando registros extemporâneos, o art. 37 da Recomendação trata da sua necessidade de atualização constante.

\section{Mecanismos alternativos de SOluÇÃo de litígios COLETIVOS}

Um dos destaques da Recomendação é o incentivo das formas judiciais e extrajudiciais para a solução de conflitos coletivos. Pretendendo alterar especialmente a postura de grandes empresas no mercado consumidor, que terão a certeza de que não mais ficarão impunes da reparação dos danos a grandes grupos de consumidores, a Recomendação trouxe previsão da combinação da forma adjudicativa das ações coletivas com solução consensual de conflitos, através da mediação, com possibilidade de realização antes do processo ou em seu curso, desde que haja consentimento das partes, na busca da compensação de danos. Todavia, a proteção do consumidor é compreendida como o cenário mais propício à aplicação dos meios alternativos, mas, a partir do texto da recomendação, espera-se implementar a mediação em áreas também como a de direitos trabalhistas e no direito ambiental ${ }^{22}$.

22 HODGES, Christopher. Developments in Collective Redress in the European Union and United Kingdom 2010. Disponível em http://globalclassactions.stanford.edu/sites/default/ 
A mediação enquanto técnica aplicada aos direitos coletivos não é uma novidade na Europa ${ }^{23}$, tanto que já gerou 1,2 milhão de euros em indenização, em pouco mais de 260 mil disputas ${ }^{24}$. Contudo, a técnica é bem acolhida por consumidores e especialistas em processo civil, mas não pelas grandes empresas e membros dos governos nos países integrantes do bloco ${ }^{25}$.

O processo fica suspenso até que se celebre o acordo ou que uma das partes desista de prosseguir na tentativa de solução amigável. A determinação europeia, porém, é de um controle judicial sobre a solução consensual. O art. 28 alerta que, para a proteção dos direitos coletivos, a legalidade do acordo alcançado deve ser verificada pelos tribunais, como uma salvaguarda para assegurar uma tutela adequada dos interesses da classe.

\section{CUSTAS PROCESSUAIS, hONORÁRIOS ADVOCATÍCIOS E FINANCIAMENTO}

Contrariando as previsões da Resolução do Parlamento Europeu, que, em seu artigo 20 atribuíam as custas processuais à regulamentação de cada Estado Membro, a preocupação com as elevadas custas processuais ${ }^{26}$, que são um empecilho em 8 dos 27 países membros da União Europeia ${ }^{27}$ fez com que a Comissão optasse por dispor sobre o tema, junto com os honorários advocatícios.

files/documents/1010\%20Class\%20Actions\%20UK\%202010\%20Report.pdf. Acesso em 09 abr. 2014.

23 No Reino Unido, por exemplo, o questionamento que está em pauta desde 2010 é a harmonização da tutela coletiva com os mecanismos alternativos de solução de conflitos, especialmente tentando redefinir uma política de custos processuais e de honorários advocatícios. A proteção do consumidor é compreendida como o cenário mais propício à aplicação dos meios alternativos, mas espera-se implementar a mediação em áreas também como a de direitos trabalhistas e no direito ambiental. (HODGES, Christopher. Developments in Collective Redress in the European Union and United Kingdom 2010. Disponível em http:// globalclassactions.stanford.edu/sites/default/files/documents/1010\%20Class\%20Actions\%20 UK\%202010\%20Report.pdf. Acesso em 09 abr. 2014).

24 HODGES, Christopher. Collective Redress: A Breakthrough or a Damp Sqibb? Trabalho no prelo.

25 UNIÃO EUROPEIA. Rumo a um quadro jurídico horizontal europeu para a tutela coletiva. Disponível em https://toad.eesc.europa.eu/ViewDoc.aspx?doc...2013_00_00. Acesso em 12 abr. 2014.

26 HODGES, Christopher, VIGENAUER, Stefin; e TUliBACKA, Magdalena. The Costs and Funding of Civil Litigation: a Comparative Perspective. Oxford e Portland: Oregon, 2010.

27 EUROPEAN AGENCY FOR FUNDAMENTAL RIGHTS. Access to justice in Europe: an overview of challenges and opportunities. Luxemburgo: Publications Office of the European Union, 2011, p. 38. 
O artigo 13 consagra a regra da sucumbência, denominada "perdedor-pagador", em que a parte que sucumbir deverá arcar com os custos (custas processuais e honorários advocatícios) da parte vencedora da demanda e os artigos 29 e 30 tratam dos honorários advocatícios. O artigo 29 dispõe que os honorários devem ser calculados sem incentivar a litigância. Excepcionalmente, os direitos nacionais poderão condicionar o honorário advocatício ao êxito e, no caso de tutela coletiva, devem regulamentar esses honorários considerando ao valor da compensação recebido pelo autor.

Já o financiamento ao litígio é um investimento realizado por uma entidade estatal ou privada, em qualquer caso em que se avalie uma perspectiva de êxito, conduzido por uma equipe qualificada, na expectativa de uma recompensa financeira. Não há este cenário no Brasil, em virtude da amplitude do sistema de assistência judiciária gratuita e os baixos custos processuais, se comparados com os valores europeus e norte-americanos, mas é tema controverso no cenário internacional e aplicável apenas à tutela ressarcitória, porque o valor financiado é avaliado em função do risco da demanda ser julgada improcedente, da quantificação do direito pleiteado e do risco de insolvência do réu ${ }^{28}$.

Embora as ideias que tenham sido trazidas à tona antes da elaboração da Recomendação indiquem que não deveria ser abordado o financiamento ao litígio, porque não contemplada nos ordenamentos nacionais, preocupada com a problemática emergente, a Comissão resolveu dispor sobre o tema. Para evitar abusos no litígio decorrente de um alto financiamento obtido, dispõe, no art. 14 da Recomendação, que a parte deve declarar a origem dos valores que utilizará para a ação e o tribunal poderá suspender o processo financiado (art. 15), se houver conflito de interesses entre o terceiro, por um lado, e o requerente e seus membros, por outro; o terceiro não dispuser de recursos suficientes para cumprir os seus compromissos financeiros para com a parte requerente que intenta a ação de tutela coletiva ou o requerente não dispuser de recursos suficientes para satisfazer as custas da parte adversa, caso seja vencido na ação de tutela coletiva.

Porém, todas as disposições são feitas em relação a entidades privadas, sem nada mencionar sobre financiamento pelo governo. Veda-se, a entidades privadas, receber a recompensa por cobrança de juros, tentar influenciar o litígio, com a celebração de um acordo, ou financiar um litígio contra a sua concorrente.

28 HODGES, Christopher; PEYSNER, John; NURSE, Angus. Litigation Funding: Status and Issues. Oxford: CSLS, janeiro de 2012, p. 2. Disponível em http://www.csls.ox.ac.uk/documents/ReportonLitigationFunding.pdf. Acesso em 14 abr. 2014. 


\section{A implementaÇÃo Da RECOMENDAÇÃo NOS PAÍSES EUROPEUS}

Em 11 de junho de 2013, através da edição da Recomendação, a União Europeia trouxe uma das previsões mais relevantes em termos de processo coletivo. Embora a Recomendação tradicionalmente não tenha força vinculante, seu próprio texto trouxe a previsão de sua implementação até 26 de julho de 2015 (art. 38), com estatísticas apresentadas até 26 de julho de 2016 (art. 40) e apreciação de sua aplicação em 26 de julho de 2017 (art. 41). Isso significa que todos os países membros da União Europeia precisarão implementar, já observando o modelo europeu, ou adequar seu sistema ao modelo previsto na Recomendação.

A Recomendação de 11 de junho de 2013 teve repercussão no âmbito da própria União Europeia, tanto que, em 11 de dezembro de 2013, com relatoria de Fran von Fürstenwerth, foi editado um Parecer do Comitê Econômico e Social, responsável por zelar pelos direitos coletivos no bloco, sobre o Comunicado editado em conjunto com a Recomendação de 11 de junho de $2013^{29}$, a partir da reunião realizada em 10 de dezembro de 2013, por 161 votos a 2 e 7 abstenções.

O referido parecer reconheceu a implementação das ações coletivas em todos os Estados Membros como uma necessidade, mas criticou que só tenha ocorrido de forma expressa em 2013, porque as ações coletivas são de interesse tanto dos cidadãos, como das empresas como dos próprios governos, por assegurarem o respeito aos direitos assegurados na legislação e a confiança do público em empresas que respeitam esses direitos. Opinou, ainda, que a Recomendação pode não ser suficiente para assegurar a uniformidade desejada, aconselhando a edição de uma diretiva com mesmo conteúdo e aconselhou que, além do opt in como sistema de vinculação, seja também admitido o opt out, quando um grande número de pessoas lesadas tenham sofrido um prejuízo ínfimo.

É elogiada a intenção de se evitar abusos por meio das salvaguardas e a previsão da tutela tanto inibitória como ressarcitória. Os honorários advocatícios, as custas e a admissibilidade da demanda coletiva são pontos a que se sugere especial ênfase dos Estados-Membros para assegurar o funcionamento do sistema de ações coletivas sem abusos e sem custos elevados. Elogia, também, a previsão dos mecanismos de solução alternativa de conflitos como complementar às ações coletivas e destaca que essas precisam, ainda, de um maior regramento, especialmente em relação ao financiamento de litígios cole-

29 UNIÃO EUROPEIA. Parecer do Comitê Econômico e Social sobre o Comunicado editado em conjunto com a Recomendação de 11 de junho de 2013. Disponível em http://ec.europa.eu/ prelex/detail_dossier_real.cfm?CL=en\&DosId=202773. Acesso em 11 abr. 2014. 
tivos e às ações coletivas transfronteiriças, acreditando não serem suficientes as disposições trazidas pela recomendação. Destaca a relevância atribuída ao papel dos juízes na análise da admissibilidade de uma ação coletiva e critica as ações de seguimento coletivas, afirmando que, se há a possibilidade de violação de um direito reconhecido no bloco, não se deve aguardar a conclusão do processo administrativo para a tutela deste direito, bem como se deveria incorporar ao texto a necessidade de compensação integral do dano sofrido.

Apesar de todas as críticas e elogios apontados no parecer, a Recomendação já parece ter uma repercussão prática em termos de ações coletivas na União Europeia. Na Holanda, por exemplo, pouco após a Recomendação, teve advento uma alteração na legislação de acordo coletivo, que vigorou a partir de $1^{\circ}$ de julho de 2013, editada em observância às discussões sobre processo coletivo no bloco. A Lei Holandesa 2.005 regulamenta os acordos em ações coletivas, que devem ser submetidos ao Tribunal de Amsterdã. A alteração ocorreu no art. 63, para permitir a aplicação também aos casos de falência e introduziu a possibilidade de se requerer uma audiência prévia ao tribunal entre o legitimado coletivo e os causadores do dano para verificar se o acordo é possível e quais seriam as melhores condições para a reparação da lesão. Passou-se, após a alteração, a admitir que o tribunal rejeite a homologação do acordo, sugerindo a reformulação de seus termos, e a possibilidade do opt out antes da celebração do acordo ${ }^{30}$.

A Bélgica também tem em tramitação um projeto de lei sobre ações coletivas, que traz a previsão de uma representatividade adequada; uma fase de admissibilidade de uma ação como coletiva e, após, o encaminhamento do caso a uma sessão de mediação, em que, se houver acordo, este será submetido à homologação pelo juiz. Essas disposições também já de acordo com as previsões de solução alternativa de conflitos da Recomendação ${ }^{31}$.

No Reino Unido, já observando os antecedentes da Recomendação e suas discussões, tenta-se incentivar os mecanismos alternativos de solução de conflitos nas ações coletivas ${ }^{32}$ e aperfeiçoar a defesa da concorrência.

30 VOET, Stefaan. European collective redress developments, p. 13-15. Disponível em http:// papers.ssrn.com/sol3/papers.cfm?abstract_id=2318809. Acesso em 11 abr. 2014.

$31 \quad$ VOET, Stefaan. Op. cit., p. 19.

32 REINO UNIDO. Private Actions in Compwtition Law: a consultation on options for reform, janeiro de 2013, p. 44-54. Disponível em https:/www.gov.uk/government/uploads/system/ uploads/attachment_data/file/70185/13-501-private-actions-in-competition-law-aconsultation-on-options-for-reform-government-response1.pdf. Acesso em 10 abr. 2014. 


\section{CONSIDERAÇões Finais}

As ações coletivas não são assunto recente na União Europeia, mas, até então, o tema era tratado por diretivas, que necessitam ser internalizadas para os ordenamentos nacionais, gerando maior ou menor grau de flexibilidade. Foi com a Recomendação de 11 de junho de 2013, que se buscou instituir um modelo para as ações coletivas, que deve ser observado por todos os Estados Membros, com implementação até 26 de julho de 2015 (art. 38), com estatísticas apresentadas até 26 de julho de 2016 (art. 40) e apreciação de sua aplicação até 26 de julho de 2017 (art. 41).

A Recomendação veio com uma nítida preocupação de ampliar o acesso à Justiça, incentivando a tutela inibitória, especialmente em matéria ambiental, onde ainda foi encontrado um déficit no bloco, e a tutela ressarcitória, especialmente em matéria consumerista, para evitar que danos de bagatela fiquem sem reparação. Reflete, ainda, uma preocupação com casos transfronteiriços, assegurando o avanço no processo de integração, ao prever a legitimidade de entidades estrangeiras, e preocupa-se que os custos que hoje são um entrave na União Europeia não impeçam o funcionamento das ações coletivas. Também evita o uso abusivo das ações coletivas, vedando, por exemplo, s indenizações punitivas, dispondo sobre a admissibilidade da ação coletiva e a preocupandose com a divulgação de informações sobre as ações coletivas, inclusive por meio de um cadastro.

Eventuais críticas ao seu texto, como, por exemplo, as disposições sobre as ações de seguimento e a limitação do cadastro de ações coletivas apenas a cada país, sem haver um registro no âmbito do bloco, poderão ser superadas quando da revisão de sua aplicação, que trará ainda mais destaque e relevância do direito processual coletivo para a União Europeia.

\section{REFERÊNCIAS}

ALVAREZ, Alejandro Bugallo. Análise Econômica do Direito: contribuições e desmitificações. Revista Direito, Estado e Sociedade. Rio de Janeiro: PUC-Rio, v. 9, n. 29, jul.-dez. 2006. pp. 49-68.

EUROPEAN AGENCY FOR FUNDAMENTAL RIGHTS. Access to justice in Europe: an overview of challenges and opportunities. Luxemburgo: Publications Office of the European Union, 2011.

GOZZOLI, Maria Clara; CIANCI, Mirna; CALMON, Petrônio; QUARTIERI, Rita. Em Defesa de um Novo Sistema de Processos Coletivos. Estudos em Homenagem a Ada Pellegrini Grinover. São Paulo: Saraiva, 2010. 
GRINOVER, Ada Pellegrini; WATANABE, Kazuo; MULLENIX, Linda. Os Processos Coletivos nos Países de Civil Law e Common Law: uma análise do direito comparado. São Paulo: RT, 2007.

HARBOUR, Laurel J.; SHELLEY, Marc E. The Emerging Euroepan Class Action: Expanding Multi-Party Litigation to a Shrinking World. 2006 ABA Annual Meeting, Section of Litigation, August 3-6, 2006, The Emerging European Class Action. Disponível em http://www.americanbar.org/tools/digitalassetabstract.html/content/dam/aba/migrated/litigation/mo/premium-lt/ prog_materials/2006_abaannual/04b.pdf. Acesso em: 13 abr. 2014.

HENSLER, Deborah. The Globalization of Class Actions: An Overview. In: HENSLER, Deborah H; ; HODGES, Christopher; TULIBACKA, Magdalena. The Annals of the American Academy of Political and Social Science. Filadélfia: SAGE, v. 622, March 2009, pp. 7-29.

HODGES, Christopher. Collective Redress: A Breakthrough or a Damp Sqibb? Trabalho no prelo.

. Developments in Collective Redress in the European Union and United Kingdom 2010. Disponível em http://globalclassactions.stanford.edu/sites/ default/files/documents/1010\%20Class \%20Actions\%20UK\%202010\%20 Report.pdf. Acesso em 09 nov. 2013

. European Union Legislation. In: HENSLER, Deborah R.; HODGES, Christopher; TULIBACKA, Magdalena. The Annals of the American Academy of Political and Social Science. Pensilvânia: SAGE, v. 622, março de 2009, pp. 78-85.

. Summary of European Union Developments. [S.1.: s.n.], p. 2-3. Disponível em http://globalclassactions.stanford.edu/content/global-class-actions-project-summary-european-developments. Acesso em: 13 jul. 2013.

; MONEY-KIRLE, Rebecca. European Collective Action: Toward Coherence? Maastricht Law Journal of European and Comparative Law. Maastricht: Maastricht Law School, vol. 19, n. 4, 2012, pp. 477-504.

.MONEY-KIRLE, Rebecca. Safeguards in Collective Actions. Oxford: The Foundation for Law, Justice and Society (FLJS), p. 2. Disponível em www.fljs.org. Acesso em 25 mar. 2014.

; PEYSNER, John; NURSE, Angus. Litigation Funding: Status and Issues. Oxford: CSLS, janeiro de 2012, p. 2. Disponível em http://www.csls.ox.ac.uk/ documents/ReportonLitigationFunding.pdf. Acesso em 14 abr. 2014.

. VIGENAUER, Stefin; e TULIBACKA, Magdalena. The Costs and Funding of Civil Litigation: a Comparative Perspective. Oxford e Portland: Oregon, 2010. 
MARINONI, Luiz Guilherme. Tutela Inibitória e Tutela de Remoção do Ilícito. Disponível em http://www.abdpc.org.br/abdpc/artigos/Luiz\%20G\%20 Marinoni(2)\%20-\%20formatado.pdf. Acesso em 8 abr. 2014.

MENDES, Aluisio Gonçalves de Castro. Ações coletivas e meios de resolução coletiva de conflitos no direito comparado e nacional. 3.ed. São Paulo: RT, 2012

; SILVA, Larissa Clare Pochmann da. Ações Coletivas na França. Artigo no prelo.

MULHERON, Rachel. The case for an opt-out class action for European Member States: a legal and empirical analysis. Current Law Journal Content. Washington: Washington Lee Law School, vol. 15, n. 3, verão de 2009, p.409454.

NAGAREDA, Richard Mass Tort Litigation in a World of Settlement. Chicago: Oxford University, 2007.

NUYTS, Arnaud; HATZIMIHAIL, Nikitas E. Cross-Border Class Actions.: the european way. Munique: Selp, 2013.

RUSSELL, Tiana Leia. Exporting Class Actions to the European Union. Boston University International Law Journal. Boston: Boston University, vol. 28, n. 1, primavera de 2010, pp.141-180.

SILVA, Larissa Clare Pochmann da. A Legitimidade do Indivíduo nas Ações Coletivas. Rio de Janeiro: GZ Editora, 2013.

STADLER, Astrid. The Commission's Recommendation on common principles of collective redress and private international law issues. Disponível em http://www.nipr-online.eu/Artikel.aspx?id=3112. Acesso em 14 abr. 2014.

TARUFFO, Michele. Some Remarcks on Group Litigation in Comparative Perspective. Duke Journal of Comparative E International Law. Carolina do Norte: Duke School of Law, vol. 11, 2001, pp. 405-423.

VELJANOVSKI, Cento. Third-Party Litigation Funding in Europe. Journal of Law, Economics and Policy. Londres: Gperge Mason University, vol. 8, n. 3, 2012, pp. 405-449.

VOET, Stefaan. European collective redress developments. Disponível em http:// papers.ssrn.com/sol3/papers.cfm?abstract_id=2318809. Acesso em $11 \mathrm{abr}$. 2014. 